\title{
Laparoscopic Splenectomy for Hematological Disorders
}

\author{
M. Khoursheed ${ }^{a}$ F. Al-Sayegh ${ }^{b} \quad$ I. Al-Bader ${ }^{a} \quad$ N. Kanawati ${ }^{a} \quad$ R. Maroof ${ }^{\mathrm{c}}$ \\ S. Asfar ${ }^{a}$ H. Dashtia \\ Departments of a Surgery, ${ }^{b}$ Medicine, and cPathology, Faculty of Medicine, Kuwait University, Kuwait
}

\section{Key Words}

Laparoscopy · Splenectomy · Hematological disease

\begin{abstract}
Objectives: The aim of this prospective study was to evaluate the safety and feasibility of laparoscopic splenectomy (LS) in patients with hematological disorders of the spleen. Subjects and Methods: Between 1999 and 2001, 15 patients (11 female and 4 male), with a mean age of 30 years, underwent LS after preoperative evaluation. If difficulties were encountered in LS, one trocar site incision was enlarged to $7-8 \mathrm{~cm}$ to engage the left hand for hand-assisted laparoscopic splenectomy (HALS) and the procedure was completed. Various parameters were reported, including spleen size as assessed by ultrasound scan, postoperative mortality and morbidity rates, accessory spleen removal, conversion rate, operative times and length of hospital stay. LS was successfully completed in 9 patients $(60 \%)$ and HALS was performed in 4 patients (26.6\%). Two patients required conversion to open splenectomy. Results: The mean operative time was $209 \mathrm{~min}$ and the mean hospital stay was 8.1 days. The hospital stay was significantly longer among HALS patients than LS patients. The mean age of patients and
\end{abstract}

\section{KARGER}

Fax +41613061234

E-Mail karger@karger.ch

www.karger.com
(C) 2004 S. Karger AG, Basel

1011-7571/04/0133-0122\$21.00/0

Accessible online at:

www. karger.com/mpp splenic size were associated with a significantly higher conversion rate. No deaths were attributed to the procedure. Complications occurred in 2 of 15 patients. Accessory spleens were identified in 2 patients. Conclusions: LS is both a safe and feasible procedure, but it requires great technical care to avoid serious complications.

Copyright @ 2004 S. Karger AG, Basel

\section{Introduction}

Since the first reports in the 1990s [1, 2], laparoscopic splenectomy (LS) is now considered the procedure of choice for patients requiring splenectomy. Case-controlled series favor LS over open splenectomy (OS) [3]. However, LS entails technical difficulties due to the anatomic features of the hematological diseases of the spleen that may increase postoperative morbidity. The 'anterolateral hanging spleen' technique was described by Delaitre et al. [1]. The 'posterolateral detached spleen' technique was introduced in 1993 by Park et al. [4]. With accumulating data and increasing experience, the indications and limitations of the procedure have changed and the risks of intraoperative hemorrhage and missing accessory spleens have diminished [5].
Dr. Mousa Khoursheed

Department of Surgery, Kuwait University

Faculty of Medicine, POB 24923

Safat 13110 (Kuwait)

Tel. +965 5319475, Fax +965 5319597, E-Mail khoursheed@hsc.kuniv.edu.kw 


\section{Subjects and Methods}

\section{Subjects and Preoperative Evaluation}

Between March 1999 and March 2001, 15 patients were referred for LS at the Mubarak Al-Kabeer Hospital, Kuwait. All patients presented with benign disorders requiring splenectomy (table 1). Patients were assessed preoperatively by a hematologist, and their preoperative need for blood and platelet transfusion, corticosteroids, plasmapheresis and gamma globulins was evaluated. The size of the spleen was assessed preoperatively by an ultrasound scan. One patient with thalassemia and a large spleen underwent preoperative splenic artery embolization. All patients received polyvalent, pneumococcal, meningococcal and Haemophilus influenzae vaccines at least 2 weeks prior to operation. Patients taking steroids were given preoperative and postoperative parenteral steroids until they resumed oral intake and a tapering oral steroid was started again. All patients received prophylactic antibiotics preoperatively.

\section{Operative Procedure}

The patient was placed in a right lateral decubitus position. The table was tilted to $15^{\circ}$ reverse Trendelenburg. A nasogastric tube and a Foley catheter were placed. The surgeon and the camera assistant stood on the patient's right side and the second assistant stood at the patient's left side. After pneumoinsufflation with carbon dioxide using a Veress needle, four trocars were inserted. The camera port $(5-11 \mathrm{~mm})$ was inserted just above the umbilicus and two working ports $(5-11 \mathrm{~mm})$ were inserted around the telescope in a triangulated fashion. The last (5-mm) trocar was placed more laterally on the left side in the anterior axillary line for retraction. Careful exploration for accessory spleens was performed before any dissection. The lesser sac was entered and the short gastric vessels were taken down either by harmonic scalpel or clips. The splenic artery and vein were ligated in continuity by intracorporeal suturing with silk. The splenocolic ligament was divided and the inferior polar vessels were clipped. The vessels on the hilum were then taken down individually with clips. The splenic attachments with the diaphragm were released until the spleen was totally freed. A retrieval bag was inserted, the spleen was placed into the bag, morcellated with ring forceps and removed in fragments. Care was taken not to perforate the bag during this procedure to prevent a spill of splenic tissue intraperitoneally or in the wound. An intra-abdominal drain was left in place for $24 \mathrm{~h}$. If difficulties were encountered in LS, one trocar site incision was enlarged to $7-8 \mathrm{~cm}$ to engage the left hand for hand-assisted laparoscopic splenectomy (HALS) and the procedure was completed.

Patient demographic and perioperative clinical data were collected and entered into a prospective database. Data are presented as mean and range, and groups were compared using the chi-square test and Student's t test. A p value less than 0.05 was considered significant.

\section{Results}

LS was attempted in 15 patients, 11 females and 4 males. The mean age was 30 years (range 13-45 years). The most common indication was idiopathic thrombocytopenic purpura (ITP) (table 1). The mean splenic size as measured by ultrasound examination was $12.6 \mathrm{~cm}$ (range
Table 1. Indications for surgery

\begin{tabular}{lcc}
\hline Diagnosis & \multicolumn{2}{c}{ Patients } \\
\cline { 2 - 3 } & $\mathrm{n}$ & $\%$ \\
\hline ITP & 10 & 66.6 \\
Thalassemia & 5 & 33.3 \\
Total & 15 & 100 \\
\hline
\end{tabular}

Table 2. Perioperative data

\begin{tabular}{lcrrl}
\hline & LS & HALS & OS & p \\
\hline Mean age, years & 26.8 & 31.5 & 42 & $0.04^{*}$ \\
Mean hospital stay, days & 7.2 & 10.7 & 7 & $0.04^{* *}$ \\
Mean operative time, min & 206 & 237.5 & 165 & NS \\
\hline
\end{tabular}

Statistical significance: * OS vs. LS; ** HALS vs. LS.

$8-19 \mathrm{~cm}) ; 5$ spleens were larger than $15 \mathrm{~cm}$. Two patients underwent preoperative plasmapheresis, 6 patients were given preoperative intravenous immune globulin and 10 patients with ITP were on steroid treatment preoperatively. An accessory spleen was found in 2 patients at the hilum of the spleen. Both patients had ITP, and LS was successfully completed in both of them.

LS was completed successfully in 9 patients. Two patients were converted to laparotomy and in 4 patients the procedure was completed by HALS. The reason for open conversion was large spleen size (thalassemia) in 1 patient and in the other it was bleeding (ITP). In 3 patients with thalassemia, HALS was performed because of large size of the spleen and in 1 patient with ITP it was performed because of dense adhesions to the superior pole of the spleen.

The mean operative time was 209 min (range 135280 ) and the mean hospital stay was 8.1 days (range 415). Patients with splenomegaly (spleen $>15 \mathrm{~cm}$ ) did not require a significantly longer operative time, however, the conversion rate to OS or HALS was significantly higher among these patients $(\mathrm{p}=0.003)$. The mean age of patients who had conversion to OS was higher than LS (mean 42 vs. 26.8 years; $p=0.04$ ). Furthermore, the mean hospital stay among the HALS patients was longer than in the LS group (mean 10.7 vs. 7.2; $p=0.04$ ). Other factors such as gender, indications for surgery and the use of harmonic scalpel showed no significant differences in regard to conversion rate (table 2). 
Overall, there were 2 complications: 1 patient developed a minor wound infection and another developed pulmonary embolism requiring anticoagulation therapy. There was no procedure-related mortality.

\section{Discussion}

With the advancement of laparoscopic skills and technology, LS is considered now to be a safe and effective procedure [6]. With hand-assisted devices, even massive splenomegaly is not considered a contraindication [7]. Recent studies have shown no difference in operative time, transfusion requirement, hospital stay, and morbidity or conversion rate with LS for large spleens in comparison to those of normal size [8]. Absolute contraindications to the laparoscopic approach, however, include cirrhosis with portal hypertension due to the risk of hemorrhage caused by variceal short gastric vessels and coagulopathy [9].

Preoperative assessment of splenic size by CT scan does not contribute to prediction of the risk of conversion to OS [10] and the efficacy of abdominal CT in detecting accessory spleens was only 25-28\% [11]. However, US examination is essential in hereditary spherocytosis to detect gallstones. In our study, the conversion rate to OS or HALS was significantly higher among patients with splenomegaly, as assessed preoperatively by US examination $(>15 \mathrm{~cm}, \mathrm{p}=0.003)$.

Preoperative embolization of the splenic artery has been advocated to reduce operative time and blood loss during surgery of large spleens [12]. However, because of serious complications, including severe pain and splenic abscess, this procedure has been abandoned by most authors. Furthermore, preoperative embolization did not significantly lower the risk of bleeding or of perioperative blood transfusion in LS patients [12].

We adopted the anterolateral hanging technique in our patients. Despite the slightly higher risks of pancreatic injury associated with this approach, we have not encountered this complication. Furthermore, we support others that advocate that the spleen is handled minimally, thus limiting the risks of decapsulation and splenosis. Early division of the short gastric vessels and ligation in continuity of the splenic artery allows for direct compression of the hilar vessels, better control of hemorrhage and provides access to the lesser sac to search for accessory spleens $[3,9]$.

In our study, 2 of 15 patients had accessory spleens. The reported incidence of accessory spleens varies from
12 to $41 \%[13,14]$, which may contribute to the recurrence of ITP. The possibility of a missed AS should be confirmed by denatured red blood cell scintigraphy and follow-up of patients. The anterolateral approach allows a good access to inspect possible areas for accessory spleens.

It has been shown that LS is more cost-effective than OS, despite higher operating room costs. To compensate for the increased direct operating room costs, length of hospital stay needs to be substantially reduced. Our mean operative time was $209 \mathrm{~min}$ (range 135-280). It is higher than that in other reports in the literature due to our limited experience. Splenomegaly (spleen $>15 \mathrm{~cm}$ ) however, resulted in no significant difference in the operative time. However, the conversion rate to OS or HALS was significantly higher among patients with large spleens ( $\mathrm{p}=$ $0.003)$.

Large spleens are difficult to handle laparoscopically because of the risk of bleeding, fragmentation and consequent need for conversion. Our open conversion rate was 2 of 15 patients. In 4 patients, a minilaparotomy was required and splenectomy was completed using HALS. This procedure enhances vascular control, retraction and manipulation $[15,16]$.

\section{Conclusion}

As a result of our experience, we think that LS is a safe and feasible procedure that is associated with a low rate of complications. It requires advanced laparoscopic skills in order to achieve a low complication rate. We have also found that HALS, in a selected group of patients, is an alternative approach to reduce the rate of open conversion, that infers a clinical advantage over open splenectomy. 


\section{References}

1 Delaitre B, Maignien B, Icard P: Laparoscopic splenectomy. Br J Surg 1992;79:1334.

2 Carroll BJ, Phillips EH, Semel CJ, Fallas M, Morgenstern L: Laparoscopic splenectomy. Surg Endosc 1992;6:183-185.

3 Diaz J, Eisenstat M, Chung R: A case-controlled study of laparoscopic splenectomy. Am J Surg 1997;173:348-350.

4 Park A, Gagner M, Pomp A: The lateral approach to laparoscopic splenectomy. Am J Surg 1997;173:126-130.

5 Gigot JF, Lenegele B, Gianello P, Etienne J, Claeys N: Present status of laparoscopic splenectomy for hematologic diseases: Certitudes and unresolved issues. Semin Laparosc Surg 1998;5:147-167.

6 Glasgow RE, Mulvihill SJ: Laparoscopic splenectomy. World J Surg 1999;23:384-388.

7 Greene AK, Hodin RA: Laparoscopic splenectomy for massive splenomegaly using a Lahey bag. Am J Surg 2001;181:543-546.
8 Targarona EM, Espert JJ, Balague C, Piulachs J, Arligas V, Trias M: Splenomegaly should not be considered a contraindication for laparoscopic splenectomy. Ann Surg 1998;228:35-39.

9 Katkhouda N, Mavor E: Laparoscopic splenectomy. Surg Clin N Am 2000;80:1285-1297.

10 Katkhouda N, Waldrep DJ, Feinstein D, Soliman H, Stain S, Ortega A, Mouiel J: Unresolved issues in laparoscopic splenectomy. Am J Surg 1996;172:585-589.

11 Gigot JF, Jamar F, Ferrant A, van Beers BE, Lengele B, Pauwels S, Pringot J, Kestens P, Gianello P, Detry R: Inadequate detection of accessory spleens and splenosis with laparoscopic splenectomy: A shortcoming of the laparoscopic approach in hematological diseases. Surg Endosc 1998;12:101-106.
12 Poulin EC, Thibault C, Mamazza J: Laparoscopic splenectomy. Surg Endosc 1995;9:172176.

13 Targarona EM, Espert JJ, Balague C, Sugranes G, Ayuso C, Lomena F, Bosch F, Trias M: Residual splenic function after laparoscopic splenectomy: A clinical concern. Arch Surg 1998;133:56-60.

14 Park A, Birgisson G, Mastrangelo M, Marcaccio M, Witzke D: Laparoscopic splenectomy: Outcomes and lessons learned from over 200 cases. Surgery 2000;128:660-667.

15 Ballaux KEW, Himpens JM, Leman G, Van den Bossche MRP: Hand-assisted laparoscopic splenectomy for hydatid cyst. Surg Endosc 1997;11:942-943.

16 Meijer DW, Bannenberg JJG, Jakimowiez JJ: Hand-assisted laparoscopic surgery: An overview. Surg Endosc 2000;14:891-895. 